\title{
Foreword and Critical Remarks
}

\section{J ohn S. Strauss}

Department of Dermatology, University of lowa, lowa City, lowa, USA

The acne symposium held at the 20th World Congress in Paris in July 2002 was an opportunity for some of those working in the field to present their findings on a wide selection of topics related to the pathogenesis and treatment of acne. The presentations were indeed world-wide, including investigators from Argentina, Chile, France, Germany, Japan, Taiwan, United Kingdom, United States, and Venezuela. As is appropriate for the World Congress which is held every 5 years, these papers are a comprehensive review of the past, present, and future. The publication of these nine papers as a unit in this journal covers varying points of view, and is an excellent reference source for all those interested in acne. There is a need to focus our attention on acne, as it should not be forgotten that in developed countries, it is still responsible for more visits to the dermatologist than any other skin disease.

A basic theme that runs throughout the nine papers is the importance of the four principles of treating acne, proposed many years ago by Kligman and myself. These include correcting the altered pattern of keratinization, the inhibition of Propionibacterium acnes and the production of extra-cellular pro-inflammatory products, the inhibition of sebum, and producing an anti-inflammatory effect. Almost all of the therapeutic approaches summarized in the presentations are related to these principles, and as is often mentioned, while we have made tremendous strides and are eminently successful in the management of acne, we cannot rest on our laurels. The management of acne will change in the future, and indications of this are contained in the papers.

\begin{tabular}{ll}
\hline KARGER & ( 2003 S. Karger AG, Basel \\
1018-8665/03/2061-0005\$19.50/0 \\
$\begin{array}{l}\text { Fax +4161306 1234 } \\
\begin{array}{l}\text { E-Mail karger@karger.ch } \\
\text { www.karger.com }\end{array}\end{array}$ & $\begin{array}{l}\text { Accessible online at: } \\
\text { www.karger.com/drm }\end{array}$
\end{tabular}

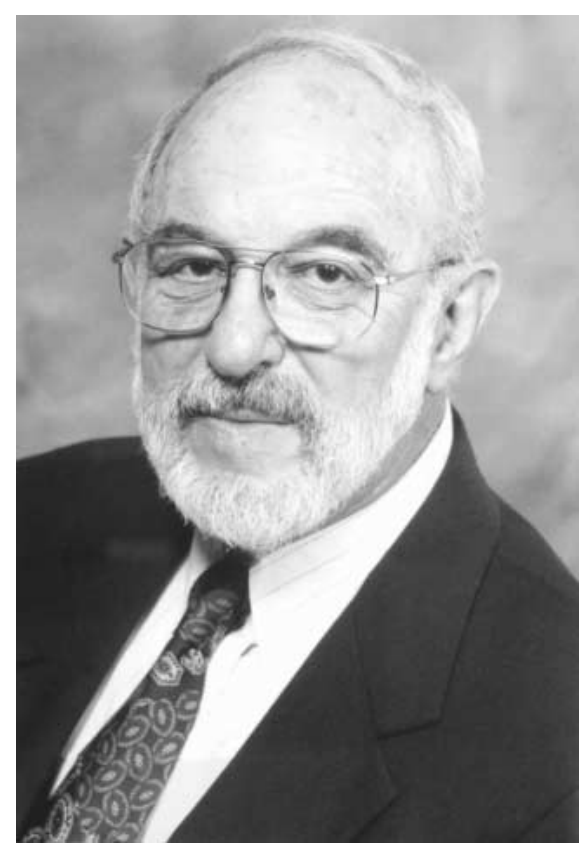

I will not comment on all the aspects of these papers, nor can I predict the future with any certainty. Nonetheless, I want to emphasize three points. First of all, we must now reassess antibiotic care for acne. Antibiotics have been a cornerstone of our care, as pointed out by Eady and co-authors. However, the development of $P$. acnes resistance to the macrolides, and to a lesser degree the tetracyclines, has to dictate changes in our practice. We should limit the use of antibiotics to the treatment of the acute

\footnotetext{
John Strauss, MD

12 Brickwood Circle NE

Iowa City, IA 52240 (USA)

Tel +13193516655, Fax +13193566366
} 
inflammatory phase of acne, probably curb the use of suboptimal doses of antibiotics, limit the use of oral erythromycin for acne to those in whom tetracyclines are contraindicated (such as children under 8 years of age and pregnant or nursing mothers), and combine topical antibiotics with benzoyl peroxide. The use of benzoyl peroxide should prevent the emergence of resistance strains of P. acnes.

My second point relates to the report by Toyoda and Morohashi, who have found immunoreactive nerve fibers containing substance $\mathrm{P}$ in close apposition to the sebaceous glands, and have also found the expression of neural endopeptidases in the germinative cells of the sebaceous glands of those with acne. These authors have also found an increase in the nerve fibers around the sebaceous glands in acne patients. These findings have great potential importance in understanding the control of the sebaceous gland stimulation, as well as inflammation. This may be the basis for a whole new group of therapeutic agents.
My last comment relates to future developments as mentioned throughout most of the papers. I want to emphasize in particular the concepts mentioned by Zouboulis and Piquero-Martin, as well as Thiboutot and Chen. Their concepts of the control of the sebaceous glands are leading us to consider the roles of leukotrienes, transcription factors, insulin-sensitizing agents, peroxisome proliferator-activated receptors (PPAR), 5 $\alpha$-reductase, antisense oligonucleotides and Toll-like receptors, just to mention a few new substances that may be found to be the key regulating agents for the sebaceous glands. Within this group may be the future controlling mechanism for the sebaceous glands and acne.

We are in an exciting molecular biology era, both in terms of mechanisms as well as potential therapies. It is interesting to think about the topics which will be discussed at the next World Congress of Dermatology in 2007, and, in particular, to follow the development of the concepts put forth during the 2002 symposium, as described in these proceedings. 